\title{
Práticas socioeducativas do projovem urbano em um presídio do Nordeste brasileiro
}

\author{
Socio-educational practices of the projovem urbano in a Brazilian Northeast prison \\ Prácticas socioeducativas del proyecto urbano en cárceles Noreste de Brasil
}

Recebido: 07/07/2021 | Revisado: 19/07/2021 | Aceito: 24/07/2021 | Publicado: 01/08/2021

\author{
Maria Lindalva Alves da Silva \\ ORCID: https://orcid.org/0000-0002-1555-1521 \\ Fundação Oswaldo Cruz, Brasil \\ E-mail: marialindalvaa@gmail.com \\ Polyanna Araújo Alves Bacelar \\ ORCID: https://orcid.org/0000-0002-6509-2327 \\ Fundação Oswaldo Cruz, Brasil \\ E-mail: polyannabio_gen@hotmail.com \\ Jéssica Pereira dos Santos \\ ORCID: https://orcid.org/0000-0002-1639-517X \\ Fundação Oswaldo Cruz, Brasil \\ E-mail: jessica.ssantos87@gmail.com \\ Liana Maria Ibiapina do Monte \\ ORCID: https://orcid.org/0000-0002-8339-8477 \\ Fundação Oswaldo Cruz, Brasil \\ E-mail: lianaibiapina@yahoo.com.br \\ Elaine Ferreira do Nascimento \\ ORCID: https://orcid.org/0000-0002-1632-9148 \\ Fundação Oswaldo Cruz, Brasil \\ E-mail: negraelaine@gmail.com
}

\begin{abstract}
Resumo
O ProJovem Urbano/prisional no Piaú foi implementado em duas unidades prisionais: Penitenciária Feminina de Teresina e Penitenciária Regional Irmão Guido. O artigo é um relato de experiência que objetivou descrever uma ação educativa do ProJovem Urbano/Prisional realizada na Penitenciária Regional Irmão Guido, Teresina, Piauí. A atividade pedagógica fez parte do Plano de Ação Articulado (PLA), elaborado e executado sob a orientação das educadoras do componente curricular das áreas de Linguagem, Matemática, Ciências Humanas e Ciências da Natureza, de janeiro de 2019 a janeiro de 2020. O desenvolvimento do projeto ocorreu em duas etapas: na primeira; realizou-se o diagnóstico sobre as condições socioambientais do sistema prisional, intitulado "Mapa dos desafios", com base na cartilha do PLA sobre causas e/ou soluções de problemas encontrados no Presídio. Na segunda etapa; ocorreu a realização da capina, construção de novos canteiros e escolha das hortaliças e plantas medicinais. Foram construídos 11 canteiros para cultivo das seguintes hortaliças: cebolinha, coentro, pimentão, alface, couve-folha, cenoura, tomates e plantas medicinais como mastruço, capim-santo, boldo, hortelã, erva-cidreira, manjericão, entre outras. As ações educativas teórico-práticas colaboraram para o desenvolvimento de habilidades socioemocionais e cognitivas, além de contribuir com o processo de ressocialização e inclusão social dos reeducandos.
\end{abstract}

Palavras-chave: Educação de jovens e adultos; Horta comunitária; Reeducandos; Ressocialização.

\begin{abstract}
ProJovem Urbano/Prison in Piauí was implemented in two prisons: Women's Penitentiary in Teresina and Regional Penitentiary Irmão Guido. The article is an experience report that aimed to describe an educational action of ProJovem Urbano/Prison held at the Regional Penitentiary Irmão Guido, Teresina, Piauí. The pedagogical activity was part of the Articulated Action Plan (PLA), prepared and executed under the guidance of educators of the curricular component in the areas of Language, Mathematics, Human Sciences and Natural Sciences, from January 2019 to January 2020. Development of the project took place in two stages: in the first; a diagnosis was carried out on the socio-environmental conditions of the prison system, entitled "Challenge Map", based on the PLA booklet on causes and/or solutions to problems found in the Prison. In the second step; weeding, construction of new flower beds and choice of vegetables and medicinal plants took place. Eleven beds were built to grow the following vegetables: chives, coriander, peppers, lettuce, cabbage, carrots, tomatoes and medicinal plants such as mastruço, common grass, boldo, mint, lemon balm, basil, among others. Theoretical-practical educational actions contributed to the development of socio-emotional and cognitive skills, in addition to contributing to the process of re-socialization and social inclusion of re-educated students
\end{abstract}

Keywords: Youth and adult education; Community garden; Prisoners education; Resocialization. 


\begin{abstract}
Resumen
El ProJovem Urbano/Prisión de Piauí se implementó en dos cárceles: la Penitenciaría de Mujeres de Teresina y la Penitenciaría Regional Irmão Guido. El artículo es un relato de experiencia que tuvo como objetivo describir una acción educativa del ProJovem Urbano/Prisión realizada en la Penitenciaría Regional Irmão Guido, Teresina, Piauí. La actividad pedagógica formó parte del Plan de Acción Articulado (PLA), elaborado y ejecutado bajo la guía de educadores del componente curricular en las áreas de Lenguaje, Matemáticas, Ciencias Humanas y Ciencias Naturales, desde enero de 2019 hasta enero de 2020. Desarrollo del proyecto se llevó a cabo en dos etapas: en la primera; se realizó un diagnóstico sobre las condiciones socioambientales del sistema penitenciario, denominado "Mapa de Desafíos", a partir del folleto del PLA sobre causas y / o soluciones a los problemas encontrados en el Penal. En el segundo paso; se llevó a cabo el deshierbe, la construcción de nuevos macizos de flores y la elección de vegetales y plantas medicinales. Se construyeron once camas para cultivar las siguientes hortalizas: cebollino, cilantro, pimiento, lechuga, repollo, zanahoria, tomate y plantas medicinales como mastruço, pasto común, boldo, menta, melisa, albahaca, entre otras. Las acciones educativas teórico-prácticas contribuyeron al desarrollo de habilidades socioemocionales y cognitivas, además de contribuir al proceso de resocialización e inclusión social de los estudiantes reeducados.
\end{abstract}

Palabras clave: Educación de jóvenes y adultos; Jardín comunitário; Reeducandos; Resocialización.

\title{
1. Introdução
}

A educação é um direito de todo cidadão brasileiro, sendo um dever do Estado sua oferta independente da condição social, nacional, cultural, de gênero ou étnico-racial do indivíduo (Vieira, 2020). No caso das pessoas privadas de liberdade, esse direito, assim como outras deficiências estruturais encontradas no Sistema Prisional não era uma prioridade para o Estado Brasileiro (Oliveira, 2017; Quaresma, Dos Santos Rocha \& Cruz, 2021).

A política de acesso ao processo educativo deve ser implementada nos presídios brasileiros como estratégia de ressocialização para as pessoas que se encontram privadas de liberdade. Alguns especialistas comungam a ideia de que o castigo punitivo do indivíduo criminoso não é apenas a única forma que irá resgatá-lo para uma vida digna em sociedade, é preciso repensar, dentre outros aspectos, no processo de ressocialização como alternativa de cumprimento da pena (Baccarini, 2012). Segundo Almeida (2014), não basta apenas punir, é necessário também educar, ressocializar, tornar este indivíduo capaz de conviver pacificamente em sociedade. As atividades educativas no sistema prisional contribuem para uma ação reeducativa à pena, sobrepondo-se as demais medidas impostas pelo sistema para a ressocialização do preso (Bessil \& Merlo, 2017).

O processo de reeducação através da garantia de direitos e deveres, tais como trabalho, tratamento de saúde física e mental, integridade moral, entre outros benefícios socioemocionais, contribui para que o sujeito tenha condições de realizar alguma atividade enquanto permanece no sistema prisional (Saar \& Araújo, 2020). Assim, a educação em âmbito prisional, a exemplo de outras atividades socioculturais, possibilita às pessoas encarceradas, no que tange as condições estruturais e qualidade de vida, o regresso da sua identidade, além de fortalecer as relações interpessoais para o efetivo exercício da cidadania (Andrade, De Sousa Dias, Vasquez \& Abreu 2019).

Vale ressaltar que a Lei de Execução Penal n 7.210/84, já previa em seus art. 17 a 21, a obrigatoriedade da oferta do ensino de $1^{\circ}$ grau e profissionalizante ministrado em nível de iniciação; aperfeiçoamento técnico adequado do ensino profissional da mulher condenada à sua condição; possibilidade de convênio com entidades públicas ou particulares, que instalem escolas ou ofereçam cursos especializados; e previsão de instalação em cada estabelecimento de uma biblioteca para uso de todas as categorias de reclusos provido de livros instrutivos, recreativos e didáticos (Brasil, 1984). A Lei também possibilitou às pessoas privadas de liberdade a realização de atividades laborais com remuneração salarial (Kanaan, Souza \& Pelissari, 2020).

A obrigatoriedade de educação a todo cidadão brasileiro está respaldada nos art. 205, inciso I, e no art. 208, da Constituição da República Federativa do Brasil (1988), com o direito do ensino fundamental e gratuito, assegurando, inclusive da oferta para todos aqueles que não tiveram acesso na idade certa. Assim, na Lei de Diretrizes e Bases da Educação Nacional 
(LDBEN) no 9394 (Brasil, 1996), em seu art. 37, preconiza que os Estados assegurarão aos jovens e adultos oportunidades educacionais. A Educação de Jovens e Adultos (EJA) é a modalidade de ensino que se configura como uma garantia de direitos educativos para uma grande parcela da população com 15 anos ou mais, que não tiveram acesso ou interromperam os estudos antes de concluir a educação básica (De Souza Pinheiro, Carmo \& Ayres, 2021).

Com base no exposto, a escolaridade para população carcerária deveria fazer parte de uma política pública de acesso à educação, levando em consideração a grande quantidade de presos que não concluíram o ensino fundamental. Embora já prevista na Constituição Federal, este direito ainda não se efetivava nas prisões como uma política pública educacional (Da Silva Torres, 2020). Neste sentido, o acesso à educação no Sistema Prisional também foi respaldado pela Lei Federal $\mathrm{n}^{\circ}$ 10.172/2001 (Brasil, 2001) que instituiu o Plano Nacional de Educação e serviu de instrumento legal para assegurar a inclusão das pessoas privadas de liberdade no processo educativo (Da Silva \& Marques, 2021; Duarte \& Sivieri-Pereira, 2018).

Em 2004, a Secretaria de Educação Continuada, Alfabetização e Diversidade (SECAD) foi constituída com objetivo de contribuir com a oferta do ensino de qualidade e garantir acesso, permanência e aprendizagem de jovens e adultos, analfabetos ou com baixos níveis de escolaridade, afro-brasileiros e quilombolas, população rural, povos indígenas, indivíduos em situações de risco e vulnerabilidade social, população carcerária, adolescentes e jovens cumprindo medidas socioeducativas (Ireland, 2012; Ministério da Educação, 2004). Políticas públicas implementadas para presos condenados, provisórios e jovens que cumprem medidas socioeducativas possibilitam-lhes uma nova forma de pensar e agir dentro e fora do Sistema Prisional, além de poder contribuir com a formação profissional para o mercado de trabalho.

Diante da caracterização desse contexto e sujeitos, o artigo tem por objetivo descrever uma ação educativa do ProJovem Urbano realizada na Penitenciária Regional Irmão Guido, Teresina, Piauí, com o intuito de oportunizar aos reeducandos vivenciarem a ressocialização no que se refere ao resgate da dignidade, ao aprendizado e a integração social para sua reinserção no mercado de trabalho, após o cumprimento da pena e o retorno ao convívio em sociedade. Isto posto, justificase, pois poderá oportunizar aos reeducandos vivenciarem a ressocialização no que se refere ao resgate da dignidade, ao aprendizado e à integração social.

\section{Metodologia}

O presente estudo é de natureza qualitativa, pois permite explicar fenômenos de natureza social, além de propiciar a aproximação e o entendimento da realidade para investigação e análises das informações (Lüdke \& André, 2013). Trata-se de um relato de experiência de uma intervenção educativa realizada no Programa de Inclusão de Jovens - ProJovem/Prisional, coordenado pela Secretaria de Estado do Piauí (SEDUC-PI). Esse processo foi intitulado "Revitalização da Horta Comunitária da Penitenciária Regional Irmão Guido" e desenvolvido pelas educadoras dos componentes curriculares de Linguagens, Matemática, Ciências Naturais, Humanas e Formação Cidadã. O local de desenvolvimento foi a Penitenciária Regional Irmão Guido, que faz parte do Sistema Prisional da Grande Teresina, sendo formada por uma área administrativa e cinco pavilhões, cada um com dez celas destinadas a presos condenados e provisórios, com capacidade para 324, porém com uma lotação de 486 em 2018 (Camuri, Silva \& Silva, 2018). Além da área construída, a penitenciária tem um espaço ocioso previsto para implantação de canteiros com hortaliças e frutíferas, sob a responsabilidade de presos condenados que são beneficiados por trabalhar dentro da unidade prisional, segundo a Lei de Execução Penal.

O projeto foi realizado com a participação de reeducandos e outros detentos, sendo iniciado em janeiro de 2019 com a elaboração do Plano de Ação Articulado (PLA). Nessa etapa, foram discutidas temáticas socioambientais presentes na penitenciária com os reeducandos matriculados no Programa ProJovem Urbano/Prisional. Para a execução deste plano, realizou-se um diagnóstico sobre as condições socioambientais do Sistema Prisional, intitulado "Mapa dos desafios", e foram 
apontadas as causas e/ou soluções dos problemas encontrados no presídio, dentre as quais optou-se pela revitalização da horta comunitária a fim de tornar esse espaço mais produtivo.

Posteriormente, houve a realização de uma reunião com a gestão, educadoras, reeducandos e outros detentos para apresentação do projeto com abordagem sobre a importância da produção de verduras e legumes de forma orgânica, bem como o uso de tecnologias adaptadas para práticas agroecológicas, dando ênfase ao saber tradicional no uso e manejo da horta. Na segunda etapa, estabeleceu-se um cronograma para realização das atividades, conforme o Quadro1.

Quadro 1. Cronograma das atividades educativas desenvolvidas durante o projeto de revitalização da horta comunitária na Penitenciária Irmão Guido, Teresina, Piauí, 2019.

\begin{tabular}{|c|l|}
\hline Meses & \multicolumn{1}{c|}{ Atividades } \\
\hline \multirow{3}{*}{ Janeiro e Fevereiro } & $\begin{array}{l}\text { - visita dos reeducandos no espaço destinado à horta comunitária sob a orientação das educadoras do } \\
\text { programa Projovem Urbano; } \\
\text { - obtenção das medidas da área total do espaço físico destinado à horta comunitária; } \\
\text { - demarcação dos canteiros existentes e dos novos; } \\
\text { - capina e limpeza da área; } \\
\text { - levantamento das hortaliças cultivadas; }\end{array}$ \\
\hline \multirow{3}{*}{ Março e Abril } & $\begin{array}{l}\text { - construção dos canteiros com uso de garrafas pet e pedaços de canos PVC; } \\
\text { - escolha das hortaliças e plantas medicinais que serão cultivadas nos novos canteiros; }\end{array}$ \\
\hline Maio & - manutenção e tratos culturais diários como capinas e plantio das hortaliças e de plantas nativas; \\
\hline Junho & - primeira colheita de algumas hortaliças \\
\hline Julho a Dezembro & - pintura das placas com o nome vulgar das hortaliças e plantas medicinais; \\
\hline & $\begin{array}{l}\text { - implantação das placas com a identificação do nome vulgar das hortaliças e plantas medicinais; } \\
\text { - manutenção dos canteiros, } \\
\text { - plantio de novas mudas de hortaliças; } \\
\text { - colheita diária. }\end{array}$ \\
\hline
\end{tabular}

Fonte: Autores (2021).

No tocante à revitalização da horta comunitária, utilizaram-se as seguintes ferramentas: pá, enxada, enxadão, carrode-mão, regadores, baldes de plásticos, adubo orgânico, sementes de hortaliças, sementeira de copo descartável, tintas, pincéis, pedaços de madeiras, garrafas pet e pedaços de cano PVC. Os canteiros foram dimensionados com tamanhos de $1 \mathrm{~m}$ de largura e $11 \mathrm{~m}$ de comprimento, procedendo-se a demarcação com barbantes. O espaço permitiu a construção de 11 canteiros com cerca de $0,30 \mathrm{~m}$ de altura para facilitar a drenagem e $0,60 \mathrm{~m}$ de espaço entre canteiros para a locomoção dos reeducandos e educadoras, bem como a passagem de carro-de-mão (Figura 1). 
Figura 1. Registros fotográficos evidenciando as etapas de construção e limpeza dos canteiros (A e C), semeadura e manutenção do plantio (B, D - H).

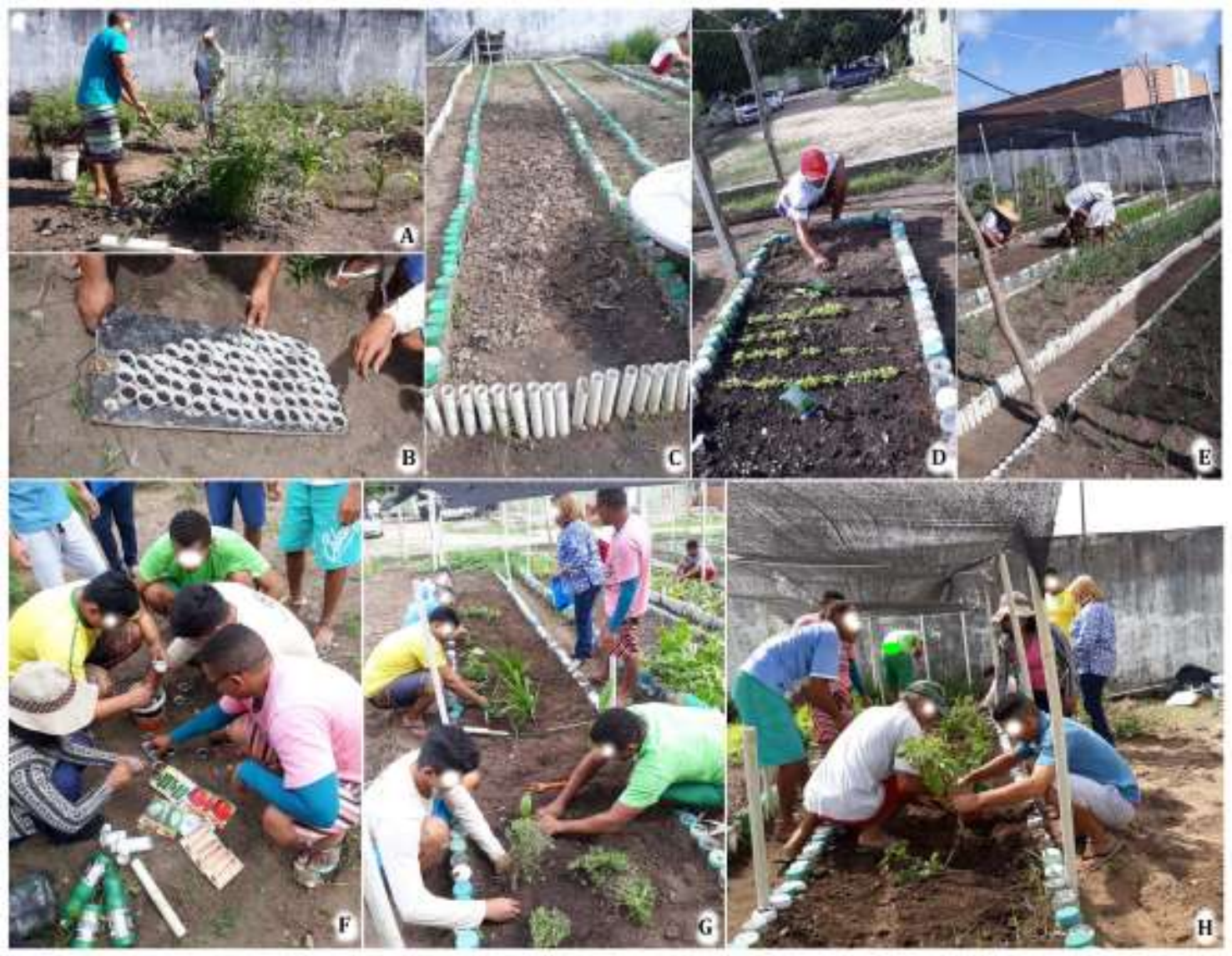

Fonte: Autores (2021).

Para o cultivo de plantas e hortaliças mais precoces, usou-se a sementeira e posteriormente houve o transplante das que germinaram para o local definitivo, de acordo com as orientações de Batista, Castro, Castro e Lima (2020), enquanto para as demais sementes, fez-se a semeadura direta. Após, os canteiros receberam cobertura com tela sombrite a fim de manter a umidade, evitar a incidência direta da luz e afugentar organismos que se alimentam de sementes. Os canteiros foram manejados de forma ecológica, evitando-se o uso de agrotóxicos contra pragas e doenças, optando-se por utilização de biofertilizantes, bio-inseticidas e adubos orgânicos, aproveitando-se os recursos naturais encontrados.

\section{Resultados e Discussão}

Programa de Educação de Jovens e Adultos como estratégia de ressocialização das pessoas privadas de liberdade

A modalidade (EJA) oportuniza aos jovens e adultos darem continuidade ao processo educativo, a partir da alfabetização à conclusão do ensino fundamental, médio ou técnico, tornando-os protagonistas de sua história no que concerne à formação profissional, além do acesso ao mercado de trabalho (Pereira, 2018). Segundo Oliveira (2017), o ensino oficial nas prisões como política pública de inserção social foi possível a partir da publicação das Diretrizes Nacionais para a Educação nas prisões e a Resolução nº 2, do Conselho Nacional de Educação/Câmara da Educação Básica (2010), por meio de debates sobre a garantia de estratégias que fortalecessem a oferta do processo educativo nos Estados e Secretarias de Educação, com oferta da modalidade EJA para jovens e adultos em situação de privação de liberdade nas instituições penais. 
Segundo dados do CNE (2010), 66\% da população presidiária não concluíram o ensino fundamental, menos de 8\% têm o ensino médio e a mesma proporção é analfabeta. A falta de escolaridade afeta especialmente os homens em idade produtiva e 3/4 dessa população possuem de 18 e 34 anos. Dentre as políticas públicas implantadas pela Secretaria de Educação Continuada, Alfabetização, Diversidade e Inclusão para jovens e adultos, ressalta-se a criação do Programa de Inclusão de Jovens - ProJovem Urbano, instituído pela Lei Federal n $n^{\circ} 11.692$ destinado a jovens de 18 a 29 anos, com o objetivo de promover sua reintegração ao processo educacional, qualificação profissional e o desenvolvimento humano (Brasil, 2008).

O ProJovem Urbano tem por objetivo, segundo o art. 11 elevar a escolaridade visando à conclusão do Ensino Fundamental, à qualificação profissional e ao desenvolvimento de ações comunitárias com exercício da cidadania na forma de curso (Brasil, 2008). No art. 81 da LDBEN (1996), reitera-se a criação de ações que promovam o acesso a continuidade dos estudos de jovens e adultos por meio da EJA ao enfatizar que é permitida a organização de cursos ou instituições de ensino experimentais, desde que obedecidas as disposições nesta lei.

O ProJovem Urbano nas prisões tornou-se realidade com a publicação da Resolução do Conselho Deliberativo do Fundo Nacional de Desenvolvimento da Educação nº 11, de 06 de setembro de 2017 (Brasil, 2017). A partir deste documento, a Secretaria de Estado da Educação do Piauí (SEDUC-PI) tornou público o edital no 15/2017 com inscrição referente ao processo seletivo simplificado para análise de currículo de educadores para vinte municípios do Piauí, dentre eles, Teresina, com a oferta em duas unidades, a Penitenciária Feminina de Teresina e Penitenciária Regional Irmão Guido.

Após a seleção, houve a contratação temporária das educadoras no segundo semestre de 2018 para áreas dos seguintes componentes curriculares: Ciências Humanas (História/Geografia); Língua Portuguesa; Língua Inglesa; Matemática; Ciências da Natureza (Ciências/Química/Física/Biologia); Arco Ocupacional na área de alimentação e Participação Cidadã, com duração de 18 meses. As educadoras participaram de uma formação específica que aconteceu no período de julho de 2018 a janeiro de 2020 para planejamento e execução das atividades pedagógicas, sob a responsabilidade da Coordenação da Unidade de Educação de Jovens e Adultos (UEJA/SEDUC-PI) e Coordenação de Ensino nas Prisões (CEP/SEJUS).

\section{Revitalização da Horta Comunitária}

Durante a execução do PLA, houve o desenvolvimento de habilidades socioemocionais, como o trabalho em equipe, espírito de confiança, cooperação e participação nas ações diárias promovendo a integração do grupo. Quanto às atividades práticas, os reeducandos tiveram estimulação cognitiva e de forma interdisciplinar nas áreas de Linguagem, Matemática, Ciências humanas e Ciências da Natureza. Isso ocorreu devido a realização de cálculos para a área total do espaço físico da horta, bem como para divisão e tamanhos dos canteiros; desenho do croqui da horta; produção de cartilha com benefícios das hortaliças na alimentação; tipos e formas de uso de plantas medicinais, uso e ocupação do espaço geográfico pelo ser humano; entre outras temáticas.

Nos canteiros construídos foram cultivadas hortaliças como cebolinha; coentro; pimentão; alface; couve-folha; cenoura; tomate e plantas medicinais, como malva-do-reino; hortelã; folha santa; coquinho; capim-santo; erva-cidreira; manjericão e mastruço (Figura 2). Também houve o manejo de 35 variedades de pimentas, bananas e mamão já cultivados ao lado da horta, de acordo os princípios técnicos dos sistemas orgânicos de produção como na permacultura e a agroecologia (Altieri, 2012). 
Figura 2. Imagens da horta ativada com as hortaliças e plantas medicinais cultivadas e identificadas (A-D), Teresina, Piauí, 2019.

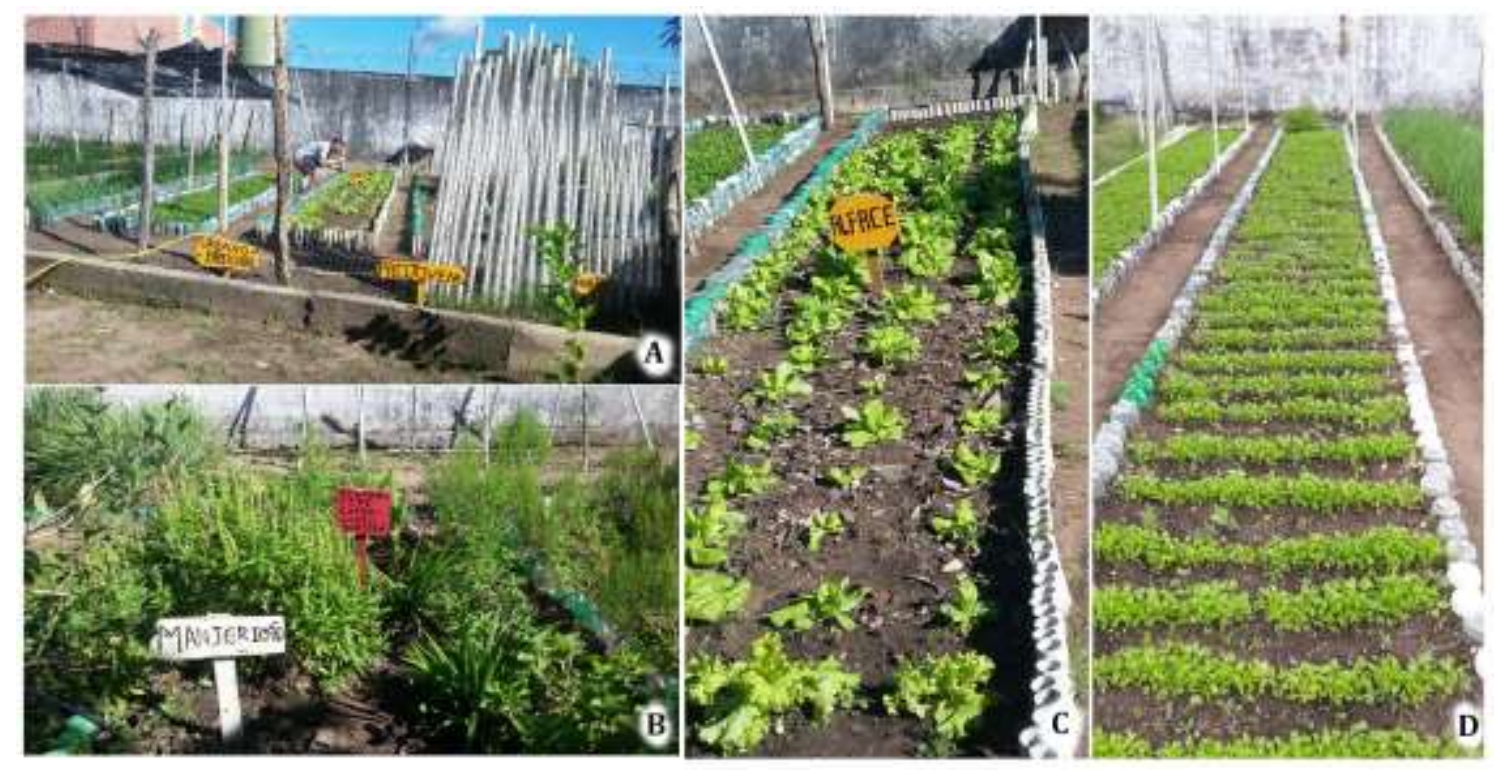

Fonte: Autores (2021).

A realização de projetos interdisciplinares como o de implantação de horta comunitária faz-se necessária em vários contextos socioambientais, pois vive-se a era em que se propaga a ideologia da sustentabilidade nos sistemas de produção em detrimento ao crescimento da população mundial e o consumismo exacerbado. Ademais, as questões ambientais tornaram-se temáticas discutidas dentro de espaços escolares, órgãos públicos, empresas, organizações não governamentais, dentre outros, a exemplo dos presídios (Oliveira, Domingos \& Colasante, 2020).

De acordo com Santos, Santos, Cabral, Santos, e Leitão (2015), atualmente há uma busca por melhor qualidade de vida representada pela integração do homem com o meio e deve ser pensada no contexto da sustentabilidade, bem como do uso racional dos recursos naturais. Assim, entende-se que o meio ambiente deve ser a preocupação de todos que fazem parte da sociedade contemporânea, independentemente da posição social e da forma de como está inserido na organização ou estrato social. Oliveira et al. (2020) argumentam que a temática ambiental deve ser abordada em qualquer cenário no processo educativo, quer seja no espaço formal, informal ou não-formal, considerando ainda qualquer nível ou modalidade de ensino.

A implantação de hortas ou pomares se transforma em uma ocupação benéfica de áreas como prédios escolares, sistemas penitenciários e em centros urbanos, que muitas vezes são utilizados como depósito de entulhos que servirão de hábitat para animais, como baratas e ratos disseminadores de doenças ou abrigo de animais peçonhentos. Transformar estes espaços em hortas colabora na produção de alimentos saudáveis e na saúde de quem os frequenta.

Desta forma, a educação é o caminho que liberta uma sociedade e promove o conhecimento relacionado ao Meio Ambiente. A revitalização da horta comunitária foi uma estratégia facilitadora do trabalho dos temas transversais meio ambiente, saúde, trabalho e consumo (Oliveira, Pereira \& Pereira Junior, 2018). Os Temas Contemporâneos Transversais (TCT) preconizados pelo novo documento da Base Nacional Comum Curricular (BNCC) (2019), orientam a inserção da temática dessas temáticas no processo educativo de forma favorecer a estimulação de estratégias que relacionem as diversas áreas dos componentes curriculares de forma que ressignifiquem os diferentes saberes de forma transversal e interdisciplinar integrando-os ao contexto social e ambiental por meio de novos conhecimentos adquiridos. De acordo com Da Conceição Ferreira, Martins, Merotto, Raggi e Da Silva (2019, p. 203) "o professor precisa aprender e descobrir novas práticas pedagógicas visando despertar a consciência da necessidade de conservar o ambiente em que vivemos, estimulando também a 
sustentabilidade". Diante dessa exposição, o projeto de revitalização da horta comunitária alinhou o conceito de sustentabilidade como estratégia de geração de renda e o cuidado ao meio ambiente.

\section{Considerações Finais}

A revitalização da horta comunitária proporcionou aos reeducandos, funcionários administrativos e aos demais presos o consumo das hortaliças cultivadas no Sistema prisional e reforçou a ideia de que é possível produzir alimentos a baixo custo e de boa qualidade, sem uso de agrotóxicos e/ou fertilizantes sintéticos. Com o desenvolvimento das ações do PLA, percebeuse a sensibilização dos reeducandos e de outros detentos para importância do uso de alimentos saudáveis na promoção da saúde, a reutilização de materiais reciclados que contribuem para o não transbordo de resíduos em terrenos baldios, com todos estes aspectos corroborando para a aquisição de conhecimentos sobre sustentabilidade e uso racional dos recursos naturais.

Durante as etapas do PLA realizadas pelos reeducandos houve o desenvolvimento de habilidades socioemocionais, como o de trabalho em equipe, de colaboração, cooperação, estimulação cognitiva e interdisciplinaridade. Dessa forma, faz-se necessário ampliar discussões sobre o processo de educação nas prisões e a divulgação de pesquisas educacionais nesta área, com perspectiva para a avaliação destas políticas implementadas no sistema prisional brasileiro.

Por acreditar que a educação é capaz de mudar concepções, valores e atitudes, cabe ao poder público ofertá-la por meio de políticas públicas a fim de proporcionar a escolarização e ressocialização dos presos na garantia da equidade no acesso ao ensino.

\section{Referências}

Almeida, S. J. (2014). A importância do trabalho na ressocialização do preso: aplicação efetiva da lei de execução penal. Instituto de ensino superior de Rio Verde. https://www.juridicocerto.com/p/almeidaadvocacia/artigos/a-importancia-do-trabalho-na-ressocializacao-do-preso-aplicacao-efetiva-da-lei-deexecucao-penal-802.

Altieri, M. (2012). Agroecologia: bases científicas para uma agricultura sustentável. Expressão Popular.

Andrade, C. P., De Sousa Dias, A., Vasquez, E. L., \& Abreu, W. F. (2019). Educação de Jovens e Adultos em contexto de privação de liberdade: análise de narrativas de um sujeito-educando. Revista Brasileira de Pesquisa (Auto) Biográfica, 4 (10), 378-393.

Baccarini, S. O. S. (2012). O Sistema Prisional e a Ressocialização. Saberes Interdisciplinares, 5 (10), 49-72.

Base Nacional Comum Curricular (2019). Temas Contemporâneos Transversais na BNCC. Proposta de Prática de Implementação de 2019. http://basenacionalcomum.mec.gov.br/images/implementacao/guia_pratico_temas_contemporaneos.pdf.

Batista, A. B. P., Castro, C. S., Castro, E. B. L., \& Lima, K. V. G. (2020). Horta caseira. Pet agronomia. UFC. https://petagronomia.ufc.br/wpcontent/uploads/2020/06/horta-pet-2.pdf.

Bessil, M. H. \& Merlo, A. R. C. (2017). A Prática Docente de Educação de Jovens e Adultos no Sistema Prisional. Psicologia Escolar e Educacional, 21 (2), $285-293$.

Brasil. (1984). Lei no 7.210, de 11 de julho de 1984. Institui a Lei de execução penal. http://www.planalto.gov.br/ccivil_03/leis/17210.htm.

Brasil. (1996). Lei $\mathrm{n}^{\mathrm{o}} 9.394$, de 20 de dezembro de 1996. Estabelece as diretrizes e bases da educação nacional. http://www.planalto.gov.br/ccivil_03/leis/19394.htm.

Brasil. (2001). Lei 10.257, de 10 de julho de 2001. Estabelece diretrizes gerais da política urbana e dá outras providências. http://www.planalto.gov.br/ccivil_03/leis/leis_2001/110257.htm.

Brasil. (2008). Lei $\mathrm{n}^{\mathrm{o}} 11.692$, de 10 de junho de 2008. Dispõe sobre o programa nacional de inclusão de jovens - projovem, instituído pela lei $\mathrm{n}^{\circ} 11.129$, de 30 de junho de 2005; altera a lei $\mathrm{n}^{\circ} 10.836$, de 9 de janeiro de 2004; revoga dispositivos das leis $\mathrm{n}^{\text {os }} 9.608$, de 18 de fevereiro de 1998 , 10.748 , de 22 de outubro de $2003,10.940$, de 27 de agosto de 2004, 11.129, de 30 de junho de 2005, e 11.180, de 23 de setembro de 2005. http://www.planalto.gov.br/ccivil_03/_ato20072010/2008/lei/l11692.htm.

Brasil. (2017). Resolução federal no 11, de 6 de setembro de 2017. Estabelece critérios e normas para os entes federados que dispõem de saldo na conta específica do programa nacional de inclusão de jovens - projovem urbano e desejam participar de edição especial do programa para entrada de estudantes em 2017 e altera a resolução $\mathrm{n}^{\mathrm{o}} 41$, de 24 de agosto de 2012. https://www.fnde.gov.br/centrais-de-conteudos/publicacoes/category/99legislacao?download=12265:resolu\%c3\%a7\%c3\%b5es-2017. 
Camuri, A. C., Silva, J. R. A., \& Silva, L. G. M. (2018). Mecanismo nacional de prevenção e combate à tortura. Relatório de missão a unidades de privação de liberdade do estado do Piauí. Brasília. https:/www.gov.br/mdh/pt-br/acesso-a-informacao/participacao-social/mecanismo-nacional-de-prevencao-ecombate-a-tortura-mnpct/relatorios-1/Relatorio_Piaui_Final_2018_28_ago.pdf.

Conselho Nacional de Educação. (2010). Câmara de Educação Básica. Resolução n. 2, de 19 de maio de 2010. Dispõe sobre as diretrizes nacionais para a oferta de educação para jovens e adultos em situação de privação de liberdade nos estabelecimentos penais. http://portal.mec.gov.br/index.php?option=com_content\&view=article\&id=14906.

Constituição da República Federativa do Brasil. (1988) Brasília. http://www.planalto.gov.br/ccivil_03/constituicao/constituicao.htm.

Da Conceição Ferreira, L., Martins, L. D. C. F., Merotto, S. C., Raggi, D. G., \& Da Silva, J. G. F. (2019). Educação ambiental e sustentabilidade na prática escolar. Revista Brasileira de Educação Ambiental, 14 (2), 201-214.

Da Silva Torres, E. N. (2020). Prisão, educação e remição de pena no Brasil: a institucionalização da política para educação de pessoas privadas de liberdade. Paco.

Da Silva, R. \& Marques, M. A. (2021). Os modelos de oferta da educação em prisões no Brasil e a construção do seu projeto político pedagógico Revista Plurais Multidisciplinar, 6 (1), 49-67.

De Souza Pinheiro, M. S., Carmo, E. M., \& Ayres, A. C. M. (2021). Política curricular de educação de jovens e adultos (EJA): considerações sobre o cotidiano da prática docente. Com a palavra, o professor, 6 (14), 46-69.

Duarte, A. J. O. \& Sivieri-Pereira, H. O. (2018). Aspectos históricos da educação escolar nas instituições prisionais brasileiras do período imperial ao século XXI. Educação Unisinos, 22 (4), 344-352.

Ireland, T. D. (2012). Educação de Jovens e Adultos como política pública no Brasil (2004 - 2010): os desafios da desigualdade e da diversidade. Instituto Paulo Freire de españa. Rhizome Freireano.

Kanaan, D. P. G., Souza, R. M., \& Pelissari, L. B. (2020). A educação como instrumento emancipatório no sistema prisional. Revista Mundi Sociais e Humanidades, 5 (3), 105-22.

Lüdke, M. \& André, M. E. D. A. (2013). Pesquisa em educação: abordagens qualitativas. E.P.U.

Ministério da Educação. (2004). Secretaria de Educação Continuada, Alfabetização e Diversidade. Relatório da Gestão da SECADI. http://portal.mec.gov.br/docman/setembro-2015-pdf/18641-secadi-relatorio-gestao-mec-2004-pdf.

Oliveira, C. B. F. (2017). A educação nas prisões brasileiras: a responsabilidade da universidade pública. Tese (doutorado) - Faculdade de educação da universidade de São Paulo, São Paulo, Brasil.

Oliveira, F. R., Pereira, E. R., \& Junior, A. P. (2018). Horta escolar, Educação Ambiental e a interdisciplinaridade. Revista Brasileira de Educação Ambiental. Revbea, 13 (2), 10-31.

Oliveira, N. A., Domingos, F. O., \& Colasante, T. (2020a). Reflexões sobre as práticas de educação ambiental em espaços de educação formal, não-formal e informal. Revista brasileira de Educação Ambiental - Revbea, 15 (7), 9-19.

Pereira, A. (2018). A educação de jovens e adultos no sistema prisional brasileiro: o que dizem os planos estaduais de educação em prisões? Revista Tempos $e$ Espaços em Educação. São Cristóvão, 11 (24), 217-252.

Quaresma, N. M. P., Dos Santos Rocha, R., \& Cruz, L. A. (2021). A pedagogia e o sistema prisional: a educação em ambiente não escolar. Revista IberoAmericana de Humanidades, Ciências e Educação, 7 (2), 18-18.

Saar, F. G. \& Araújo, A. P. G. S. (2020). A violação dos direitos humanos no sistema prisional. Jornal eletrônico Faculdade Vianna Júnior, 12 (2), 20-20.

Santos, J. J., Santos, A. L. A., Cabral, S. A. A. O., Santos, M. D. R., \& Leitão, E. T. C. (2015). Horta comunitária: instrumento de geração de renda para os pais das crianças do PETI - Satuba. In: congresso técnico científico da engenharia e da agronomia - CONTECC.

Vieira, Y. L. D. (2020). Educação como prática de ressocialização na perspectiva dos privados de liberdade da penitenciária de segurança média Juiz Hitler Cantalice: um estudo de caso. Monografia (Graduação em Pedagogia) - Universidade Federal da Paraíba, Paraíba, Brasil. https://www.repositorio.ufpb.br/jspui/handle/123456789/17639. 